\title{
Prostaglandin Analogue
}

National Cancer Institute

\section{Source}

National Cancer Institute. Prostaglandin Analogue. NCI Thesaurus. Code C78568.

Any synthetic agent that is chemically identical or similar to any of the naturally occurring prostaglandin subtypes. 